\title{
Research Article \\ Dentists Are at a Higher Risk for Oral Helicobacter pylori Infection
}

\author{
Qian Liu $\mathbb{D}^{1,2}$ Yunhan Zhang, ${ }^{1,3}$ Chunmei Xu, ${ }^{1,2}$ Boran Chen, ${ }^{4}$ Hao Xu, ${ }^{1,5}$ Yangpei Cao, ${ }^{1,6}$ \\ Tingwei Guo, ${ }^{7}$ Yuan Gao, ${ }^{1,6}$ Zhou Zhou, ${ }^{8}$ Xuedong Zhou $\mathbb{D}^{1,6}$ Xin Xu ${ }^{10},{ }^{1,6}$ and Jinzhi He $\mathbb{B}^{1,6}$ \\ ${ }^{1}$ State Key Laboratory of Oral Diseases \& National Clinical Research Center for Oral Diseases, West China Hospital of Stomatology, \\ Sichuan University, Chengdu 610041, China \\ ${ }^{2}$ Department of Periodontics, West China Hospital of Stomatology, Sichuan University, Chengdu 610041, China \\ ${ }^{3}$ Department of Pediatric Dentistry, West China Hospital of Stomatology, Sichuan University, Chengdu 610041, China \\ ${ }^{4}$ Department of Stomatology, The Third Hospital of Peking University, Beijing 100191, China \\ ${ }^{5}$ Chinese Academy of Medical Sciences Research Unit of Oral Carcinogenesis and Management, West China Hospital of Stomatology, \\ Sichuan University, Chengdu 610041, China \\ ${ }^{6}$ Department of Cariology and Endodontics, West China Hospital of Stomatology, Sichuan University, Chengdu 610041, China \\ ${ }^{7}$ Center for Craniofacial Molecular Biology, Herman Ostrow School of Dentistry, University of Southern California, Los Angeles, \\ CA 90033, USA \\ ${ }^{8}$ Clinical Skills Training Center, West China Hospital, Sichuan University, Chengdu, Sichuan, China
}

Correspondence should be addressed to Jinzhi He; hejinzhi@scu.edu.cn

Received 7 April 2020; Revised 6 June 2020; Accepted 16 June 2020; Published 6 July 2020

Academic Editor: Ali I. Abdalla

Copyright $\odot 2020$ Qian Liu et al. This is an open access article distributed under the Creative Commons Attribution License, which permits unrestricted use, distribution, and reproduction in any medium, provided the original work is properly cited.

Oral cavity has been taken as one of the major reservoirs for Helicobacter pylori, the bacteria responsible for gastric infection and cancers. Dentists are frequently exposed to saliva; thus, theoretically, they are at a higher risk for oral $H$. pylori infection. In the present study, to test this hypothesis and to find out the potential factors associated with the increased risk, a cross-sectional study was carried out on a large scale of dentists $(N=90)$ and nondentist controls $(N=110)$. By using nested polymerase chain reaction to amplify a specific DNA fragment of $H$. pylori, we found $7.27 \%$ of saliva samples from the nondentist group and $16.67 \%$ of saliva samples from the dentist group were oral $H$. pylori positive, and the difference between groups was statistically significant $\left(\chi^{2}=4.292, p=0.038\right)$. Importantly, however, after stratifying enrolled subjects with factors which might interfere with the comparison of $H$. pylori detection rate between groups, we still observed a higher $H$. pylori frequency in the dentists than that in the controls in subgroups, including those with good individual hygiene, healthy lifestyle, and physical condition, as well as those living with families to be gastric disease free and not sharing meals with $H$. pylori-positive persons, respectively. Moreover, the frequency of clinical practice per week of the investigated dentists was closely associated with an oral $H$. pylori infection risk. Our data indicates that dentists are at a higher risk for $H$. pylori infection, and intensive attention needs to be paid on this issue.

\section{Introduction}

Since its first isolation by Marshall and Warren from gastric biopsy specimens of patients with chronic gastric inflammation and peptic ulcer, Helicobacter pylori (H. pylori) has long been regarded as the main etiologic agent for chronic gastritis, type B gastritis, and peptic ulcers [1-3]. Worth still, due to its role in gastric cancers (the cancer considered as the second most frequent cause of cancer death worldwide [4]), H. pylori is a type 1 carcinogen identified by the International Agency for Research on Cancer of the World Health Organization $[2,4,5]$. Thus, the prevention of $H$. pylori infection is of great clinical significance.

$H$. pylori was also detected in human organs other than the stomach. After Krajden et al. successfully isolated $H$. pylori from dental plaque and saliva [6], the presence of this 
TABle 1: Primers used in the present study.

\begin{tabular}{lcc}
\hline & Sequence & Product \\
\hline Primer 1 & $5^{\prime}$-CCCTCACGCCATCAGTCCCAAAAA-3' & 417 bp \\
& $5^{\prime}$-AAGAAGTCAAAAACGCCCCAAAAC-3' & \\
Primer 2 & $5^{\prime}$-GCCAAATCATAAGTCCGCAGAA-3 ${ }^{\prime}$ & $230 \mathrm{bp}$ \\
\hline
\end{tabular}

bacterium in the human oral cavity has been confirmed by several other studies [7-10]. The oral H. pylori is closely associated with oral diseases, such as periodontal disease [11], dental caries [12], recurrent aphtha's stomatitis [13], and mucosal inflammation [14]. In addition, previous studies showed that $H$. pylori colonizing the oral cavity might be also involved in gastric diseases because oral $H$. pylori interfered gastric eradication therapy [15-20]. Concomitantly, gastric $H$. pylori-positive patients were more likely to be oral $H$. pylori positive [21], and identical strains of $H$. pylori in the oral cavity and in the stomach have been isolated [8-10, 22, 23]. Meanwhile, chances of occurrence or recurrence of $H$. pylori stomach infection are more likely to be found among persons who harbour this organism in the oral cavity [24]. All these reports suggest that the oral cavity is a potential reservoir of $H$. pylori before it invades gastric mucosa [7]. Therefore, the oral-oral pathway has been suggested to be among the primary routes of $H$. pylori transmission [25], making infected saliva, dental plaque, debris, and eating devices as major vehicles for $H$. pylori spreading.

Compared to the nondentists, dentists are more frequently exposed to the infected oral contents such as saliva and dental plaque. It is conceivable that dentists are at a higher risk for oral $H$. pylori infection. Therefore, the aim of this study was to compare the detection frequency of oral $H$. pylori between dentists and nondentists and to figure out the potential factors closely associated with the oral $H$. pylori infection risk among dental professionals.

\section{Materials and Methods}

2.1. Subjects Enrolling. The study protocol was reviewed and approved by the Institutional Review Board of West China Hospital of Stomatology, Sichuan University (WCHSIRBD-2015-086). Written informed consent was obtained from all participants before sample collection. In total, 96 dentists and 115 nondentists were randomly enrolled in this study from March 2016 to December 2016. Volunteers in the nondentist control group lived in Chengdu for more than 2 years at the start time point as the dentists did and did not pay a visit to a dental clinic for more than one year. Specifically, participants (1) were free of systematic diseases other than gastric diseases, (2) had no previous periodontal treatment and no antibiotic use within the past 3 months, (3) had normal oral mucosal membranes, (4) had more than 24 teeth and free of dental caries, and (5) for more than $90 \%$ checking sites, periodontal tissues showed no clinical signs of inflammation, such as redness, swelling, or bleeding on probing, and were judged to be free of gingivitis or periodontitis. Exclusion criteria included pregnancy, the occurrence of systemic diseases other than gastric diseases, receiving antibiotics, and immunosuppressive drug treatment within the past 3 months. The oral examination was carried by two trained dentists. A kappa test on both caries and periodontal diagnosis was done before sampling to assess the reproducibility of these two examiners, and the kappa values for the diagnosis of both diseases were higher than 0.8 , indicating the examination results between the two dentists were reproducible.

2.2. Sampling. Volunteers were asked to refrain from food and oral hygiene (i.e., brushing or flossing teeth) for 2 hours before sampling. Volunteers were instructed to expectorate into a sterile cryogenic vial (Corning, NY, USA). About $2 \mathrm{~mL}$ of spontaneous, unstimulated whole saliva was obtained from each individual. The saliva was put on ice immediately after sampling, transported to the laboratory within 2 hours, and stored at $-80^{\circ} \mathrm{C}$ before further processing. At the same time, subjects were asked to fill a questionnaire. The information of correlative factors contributing to $H$. pylori infection risk was collected, including demographic and socioeconomic status (i.e., age, sex, education background, residence, number of household members, and working years), lifestyle (i.e., washing hand before eating and after toilet, tooth mug sharing, dishware sharing, picky eating, drinking unboiled water, smoking, and alcohol abuse), medical history (e.g., upper gastrointestinal diseases or family member with gastric diseases), and dental professional-related factors (e.g., using PPE, dental practice frequency per week, and the number of patients treated every half-day).

2.3. DNA Extraction. TIANamp Swab DNA Kit (Tiangen Biotech, Beijing) was used to extract genomic DNA following the manufacturer's instruction. The DNA samples were stored at $-20^{\circ} \mathrm{C}$ until use.

2.4. Nested Polymerase Chain Reaction. A nested PCR technique was applied in the present study for its sensitivity and specificity. Primer sets designed specifically for $H$. pylori by Song et al. are shown in Table 1. For first PCR reaction, each $50 \mu \mathrm{L}$ PCR amplification mixture contained $1 \mu \mathrm{L}(1 \mathrm{U} / \mu \mathrm{L})$ KOD-Plus DNA polymerase High Fidelity (Invitrogen, Japan), $5 \mu \mathrm{L}$ PCR buffer for KOD-Plus, $1.5 \mu \mathrm{L}$ of each prime $(0.3 \mu \mathrm{M}), 10 \mathrm{ng}$ of genomic DNA, $5 \mu \mathrm{L}$ dNTPs $(0.2 \mathrm{mM}$ each), and $2 \mu \mathrm{L} \mathrm{Mg}^{2+}(1.0 \mathrm{mM})$. For the second reaction, each $50 \mu \mathrm{L}$ PCR amplification mixture had $1 \mu \mathrm{L}$ KOD-Plus DNA polymerase High Fidelity (Invitrogen, Japan), $5 \mu \mathrm{L}$ PCR 
TABLE 2: Clinical parameters of study populations.

\begin{tabular}{|c|c|c|c|}
\hline & Dentists & Nondentist group & Statistical analysis \\
\hline Age & $25.52 \pm 3.18$ & $32.76 \pm 12.57$ & $p<0.0001^{\mathrm{a}}$ \\
\hline Sex & & & $p=0.174^{\mathrm{b}}$ \\
\hline Male & $30(15.0 \%)$ & $47(23.5 \%)$ & \multirow{2}{*}{$\left(\chi^{2}=1.845\right)$} \\
\hline Female & $60(20.0 \%)$ & $63(31.5 \%)$ & \\
\hline Residence & & & $p=0.047^{\mathrm{b}}$ \\
\hline Urban area & $83(41.5 \%)$ & $91(45.5 \%)$ & \multirow{2}{*}{$\left(\chi^{2}=3.946\right)$} \\
\hline Rural area & $7(3.5 \%)$ & $19(9.5 \%)$ & \\
\hline Educational background & & & $p=0.677^{c}$ \\
\hline Primary schools and below & $0(0.0)$ & $15(7.5 \%)$ & \multirow{8}{*}{$(Z=-0.417)$} \\
\hline Junior middle school & $0(0.0)$ & $13(6.5 \%)$ & \\
\hline Senior school & $0(0.0)$ & $7(3.5 \%)$ & \\
\hline Junior college education & $1(0.5 \%)$ & $15(7.5 \%)$ & \\
\hline Regular college & $23(11.5 \%)$ & $32(32.5 \%)$ & \\
\hline Master & $55(27.5 \%)$ & $22(11 \%)$ & \\
\hline $\mathrm{PhD}$ and above & $11(5.5 \%)$ & $5(2.5 \%)$ & \\
\hline Unclear & $0(0.0)$ & $1(0.5 \%)$ & \\
\hline Years of working & & & $p<0.0001^{\mathrm{c}}$ \\
\hline $1-2 \mathrm{yrs}$ & $49(24.5 \%)$ & $49(24.5 \%)$ & \multirow{5}{*}{$(Z=-3.922)$} \\
\hline $3-5 \mathrm{yrs}$ & $34(17.0 \%)$ & $31(15.5 \%)$ & \\
\hline $6-10 \mathrm{yrs}$ & $6(3.0 \%)$ & $11(5.5 \%)$ & \\
\hline$>11 \mathrm{yrs}$ & $1(0.5 \%)$ & $26(13 \%)$ & \\
\hline Unclear & $0(0.0)$ & $3(1.5 \%)$ & \\
\hline
\end{tabular}

${ }^{\mathrm{a}} T$ - $t$ test; ${ }^{\mathrm{b}}$ chi-square test; ${ }^{\mathrm{c}}$ Wilcoxon rank test.

buffer for KOD-Plus, $1.5 \mu \mathrm{M}$ of each primer and $1 \mu \mathrm{L}$ amplicons from the first PCR reaction, $5 \mu \mathrm{L}$ dNTPs $(0.2 \mathrm{mM}$ each), and $2 \mu \mathrm{L} \mathrm{Mg}^{2+}(1.0 \mathrm{mM})$. The thermal cycle conditions were, for the first reaction, $94^{\circ} \mathrm{C}$ for $2 \mathrm{~min}$ followed by 40 cycles of $94^{\circ} \mathrm{C}$ for $15 \mathrm{sec}, 55^{\circ} \mathrm{C}$ for $30 \mathrm{sec}$, and $68^{\circ} \mathrm{C}$ for $1 \mathrm{~min}$ and final elongation at $68^{\circ} \mathrm{C}$ for $4 \mathrm{~min}$ and, for the second reaction, $94^{\circ} \mathrm{C}$ for $2 \mathrm{~min}$ followed by 30 cycles of $94^{\circ} \mathrm{C}$ for $15 \mathrm{sec}$, $55^{\circ} \mathrm{C}$ for $30 \mathrm{sec}$, and $68^{\circ} \mathrm{C}$ for $1 \mathrm{~min}$ and final elongation at $68^{\circ} \mathrm{C}$ for $4 \mathrm{~min}$. Positive control was conducted with purified $H$. pylori genomic DNA, while $\mathrm{ddH}_{2} \mathrm{O}$ were set as a blank control.

2.5. Gel Electrophoresis. The PCR products were visualized with 1.5\% agarose gel stained with Goldview (Biohippo, Gaithersburg, USA) under UV gel Imager (Beijing Liu Yi company and vendor location). The PCR product was about $230 \mathrm{bp}$.

2.6. Statistical Analysis. Chi-square test was used for qualitative data, and the Wilcoxon rank test was used for analysing nonparametric (interval or not normally distributed) data. To further exclude the possibility that the statistical significance between the dental and the nondental group was introduced by sampling bias, we stratified enrolled subjects with correlative factors listed above, and the $Z$ test was used to compare the detection frequency of $H$. pylori in subgrouped between dentists and nondentists. The logistic regression model was used for correlation analysis. $\alpha=0.05$ was set as the level of significance, and the statistical analysis was done with SPSS 21.0 and SAS 9.3.

\section{Results}

3.1. Overall Included Subject Information. Subjects $(N=211$, 77 males and 123 females, age: $30 \pm 11$ years) were recruited in this study. 11 subjects were further excluded due to the absence of either saliva samples or the questionnaire survey. The clinical parameters of enrolled populations are listed in Table 2. No significant difference was observed in the sex and educational background between the dentists and the nondentists (Table 2). However, the percentage of subjects living in an urban area in dentists was higher than that of nondentists $\left(p=0.047, \chi^{2}=3.946\right.$, Table 2$)$. The dentists enrolled were younger than nondentists $(25.52 \pm 3.18$ vs. $32.76 \pm 12.57$ years old, $p<0.0001$, Table 2$)$. In addition, we found that the working years between groups were different $(p<0.0001, Z=-3.922$, Table 2$)$.

3.2. Dentists Are at a Higher H. pylori Infection Risk. Approximately $10 \%$ (23 out of 200) recruited subjects were detected as salivary $H$. pylori positive, and the prevalence among males was equal to that among females (12.99\% vs. $10.57 \%$, $p>0.5, \chi^{2}=0.272$, Table 3$)$. The oral H. pylori detection rate in the saliva of dentists was $16.67 \%$ (15/90) while $7.27 \%$ $(8 / 110)$ in the control group, and the difference was statistically significant $(p=0.038$, Table 3$)$. As shown in Table 4 , 
TABle 3: Detection frequency of oral $H$. pylori in enrolled subjects.

\begin{tabular}{lcccc}
\hline & Negative & Positive & Total & $p$ value \\
\hline Nondentist & $102(51.0 \%)$ & $8(4.0 \%)$ & 110 & $p=0.038^{\mathrm{a}}$ \\
Dentist & $75(37.5 \%)$ & $15(7.5 \%)$ & 90 & $\left(\chi^{2}=4.292\right)$ \\
Male & $67(33.5 \%)$ & $10(5.0 \%)$ & 77 & \\
Female & $110(55.0 \%)$ & $13(6.5 \%)$ & 123 & $p>0.5^{\mathrm{a}}$ \\
Total & $177(88.5 \%)$ & $23(11.5 \%)$ & 200 & $\left(\chi^{2}=0.272\right)$ \\
\hline
\end{tabular}

${ }^{\mathrm{a} C h i-s q u a r e ~ t e s t . ~}$

among those with good individual hygiene (e.g., washing hand, never sharing tooth mug, and dishware), healthy lifestyle (e.g., no frequently picky eating, never drink unboiled water and alcohol, and nonsmoking), well physical condition (e.g., no symptom of gastric diseases), no families with gastric diseases, and not having meals with $H$. pylori infection, dentists still showed a higher bacterial detection frequency than the nondentists, which further supported that dentists were more vulnerable to oral $H$. pylori infection (Table 4).

3.3. Dental Practice Frequency Is Positively Correlated with the Vulnerability to Oral H. pylori Infection. Among using of PPE, dental practice frequency per week (DPF, every half-day defined as one clinical practice), and the number of patients treated every half-day, a correlation between dental practice frequency per week (DPF) and oral H. pylori detection rate in saliva was observed (Table 5). The relationship between infection possibility $(P)$ and DPF was shown with the equation as the following: $\operatorname{logit}(P)=-5.995+$ $1.776 \times \mathrm{DPF}-0.152 \times \mathrm{DPF}^{2}$. A fitting curve was generated based on the regression equation (Figure 1), and the oral $H$. pylori detection rate increased as the dental service frequency increased.

\section{Discussion}

H. pylori infection constitutes a crucial element of the pathogenesis of gastroduodenal ulcer disease, noncardia gastric diseases, and gastroesophageal reflux disease [26-30]. It has also been associated with increased risks of colon cancer [30-32], idiopathic thrombocytopenic purpura [33, 34], iron deficiency anemia [35, 36], vitamin B12 deficiency [37], and more recently, neurodegenerative disorders and metabolic syndrome [38]. Dentists might be particularly prone to $H$. pylori infection, because the oral-oral pathway is one of the primary routes of $H$. pylori transmission. $H$. pylori is able to colonize the oral cavity $[18,21,39,40]$ and is disseminated during dental procedures in the form of "aerosol cloud" [40-42]. Previous studies from the United States, Japanese and French have explored the problem of $H$. pylori infection in dental professionals using serological markers [43-45]. However, studies comparing the detection of salivary $H$. pylori between dentists and nondentists are limited. In this study, we analysed the presence of $H$. pylori in the oral cavity of dentists and nondentists, in the purpose of evaluating the higher risk of $H$. pylori infection in dental professionals.
In this study, saliva was collected, as it is heavily laden with bacteria $\left(10^{8} \sim 109 \mathrm{CFU} / \mathrm{mL}\right)$ [46], making it a perfect candidate for in vivo oral microbial investigations. Moreover, saliva collection is a noninvasive and easy means for detection compared with other oral sites [47]. The salivary detection rate of $H$. pylori in the current study was much lower than the gastric detection rate in Chinese as reported previously by others ( 40\%) [48] but was similar to the oral detection rate of $H$. pylori in Mexican asymptomatic children through PCR [49]. We confirmed that the detection frequency of oral $\mathrm{H}$. pylori in the dentists was significantly higher than that in the control group ( $16.67 \%$ vs. $7.27 \%$, $p=0.038$, Table 3). This result was consistent with other investigations $[8,44]$, supporting that dentists were at a higher risk of $H$. pylori infection. It is noteworthy to mention that some other studies have showed that there were no significant oral $H$. pylori detection differences between dentists and nondentists [50]. This disagreement might be caused by methodologies (culture, serological method, or PCR), geographic factors, etc.

To ensure our research provided an objective and comparable result, subject enrolment was strictly controlled according to the random principle. The demographic characters including the sex and educational background between the two groups were comparable. When it comes to the residence, although majority of both the enrolled dentists and nondentists lived in an urban area, a statistically significant difference was observed. Usually, people living in an urban area have more access to better sanitation in China, which is important to control microbial infection such as $H$. pylori [51-53]. However, the H. pylori infection frequency within dentists was significantly higher than that in the control group, supporting the idea that dental practicing increases the H. pylori infection risk. We further excluded the influence of confounders as shown in Table 4 by stratifying and compared the $H$. pylori infection between dentist and nondentist subgroups. After controlling these potential biases, dentists still had a higher detection rate of $H$. pylori infection. These results further support the idea that dentists are more vulnerable to oral $\mathrm{H}$. pylori colonization and highlight that dental professionals should take these issues seriously.

Furthermore, we analysed factors which might be closely associated with the infection risk among the dentists and tried to provide clues for dentists to take measures to reduce the infection risk. The factors analysed in this study included safety-personal protective equipment (PPE, such as masks, gloves, and gown), dental practice frequency per week (DPF, every half-day defined as one clinical practice), and the number of patients treated every half-day. Among them, DPF was closely related to oral $H$. pylori detection rate, as oral $H$. pylori detection rate grew as the dental practice frequency increased. The equation and the fitting curve were further applied to describe the relationship. The possible explanation was "aerosol cloud" generated during clinical practice can long-time exist [40-42]. Thus, once the dental clinic gets contaminated, without intensive disinfection measures, the increased frequency of exposure will elevate the infection risk. No significant association was observed between PPE and salivary detection rate of $H$. pylori. 
TABLe 4: Detection frequency of oral $H$. pylori in subgrouped volunteers.

\begin{tabular}{|c|c|c|c|c|c|c|}
\hline \multirow{3}{*}{ Washing hand before eating and after toilet } & \multicolumn{2}{|c|}{ Dentist } & \multicolumn{2}{|c|}{ Nondentist } & \multirow{2}{*}{$Z$ value } & \multirow{2}{*}{$p$ value } \\
\hline & \multirow[t]{2}{*}{ Total } & \multirow[t]{2}{*}{ Positive } & \multirow[t]{2}{*}{ Total } & \multirow[t]{2}{*}{ Positive } & & \\
\hline & & & & & & \\
\hline & 2 & $1(50.0 \%)$ & 5 & $0(0.0)$ & 1.708 & 0.088 \\
\hline Always & 28 & $6(21.4 \%)$ & 40 & $2(0.5 \%)$ & 2.069 & 0.039 \\
\hline Every time & 60 & $8(13.3 \%)$ & 65 & $6(9.2 \%)$ & 0.727 & 0.467 \\
\hline \multicolumn{7}{|c|}{ Tooth mug sharing } \\
\hline Never & 72 & $15(20.8 \%)$ & 85 & $5(5.9 \%)$ & 2.800 & 0.005 \\
\hline Sometimes & 15 & $0(0.0)$ & 15 & $2(13.3 \%)$ & -1.464 & 1.000 \\
\hline Always & 2 & $0(0.0)$ & 2 & $1(50.0 \%)$ & -1.155 & 1.000 \\
\hline Every time & 1 & $0(0.0)$ & 8 & $0(0.0)$ & - & - \\
\hline \multicolumn{7}{|l|}{ Dishware sharing } \\
\hline Never & 38 & $7(18.4 \%)$ & 22 & $0(0.0)$ & 2.142 & 0.032 \\
\hline Sometimes & 34 & $4(11.8 \%)$ & 16 & $2(12.5 \%)$ & -0.075 & 1.000 \\
\hline Always & 12 & $4(33.3 \%)$ & 23 & $3(13.0 \%)$ & 1.424 & 0.154 \\
\hline Every time & 6 & $0(0.0)$ & 48 & $2(4.2 \%)$ & -0.510 & 1.000 \\
\hline \multicolumn{7}{|l|}{ Picky eating } \\
\hline Sometimes & 79 & $13(16.4 \%)$ & 102 & $7(6.7 \%)$ & 2.042 & 0.041 \\
\hline Always & 11 & $2(18.2 \%)$ & 8 & $1(12.5 \%)$ & 0.335 & 0.737 \\
\hline \multicolumn{7}{|c|}{ Drinking unboiled water } \\
\hline Yes & 13 & $1(7.7 \%)$ & 24 & $2(8.3 \%)$ & -0.068 & 1.000 \\
\hline No & 77 & $14(18.2 \%)$ & 86 & $6(7.0 \%)$ & 2.177 & 0.029 \\
\hline \multicolumn{7}{|l|}{ Smoking } \\
\hline Yes & 2 & $0(0.0)$ & 8 & $2(25.0 \%)$ & -0.791 & 1.000 \\
\hline No & 88 & $15(17.0 \%)$ & 102 & $6(5.9 \%)$ & 2.447 & 0.014 \\
\hline \multicolumn{7}{|l|}{ Alcohol abuse } \\
\hline Yes & 2 & $0(0.0 \%)$ & 4 & $1(25.0 \%)$ & -0.775 & 1.000 \\
\hline No & 86 & $14(16.3 \%)$ & 106 & $7(6.6 \%)$ & 2.136 & 0.033 \\
\hline \multicolumn{7}{|l|}{ Nausea } \\
\hline Yes & 8 & $0(0.0)$ & 12 & $1(8.3 \%)$ & -0.838 & 1.598 \\
\hline No & 73 & $14(19.2 \%)$ & 87 & $7(8.0 \%)$ & 2.077 & 0.038 \\
\hline Not sure & 6 & $1(16.7 \%)$ & 10 & $0(0.0)$ & 1.333 & 0.182 \\
\hline \multicolumn{7}{|l|}{ Gastric diseases } \\
\hline Yes & 21 & $5(23.8 \%)$ & 21 & $2(9.5 \%)$ & 1.242 & 0.214 \\
\hline No & 43 & $8(18.6 \%)$ & 66 & $3(4.5 \%)$ & 2.382 & 0.017 \\
\hline Not sure & 23 & $2(8.7 \%)$ & 21 & $3(14.3 \%)$ & -0.584 & 1.000 \\
\hline \multicolumn{7}{|c|}{ Families with gastric diseases } \\
\hline $\mathrm{F}^{\mathrm{a}}(+) \mathrm{M}^{\mathrm{b}}(-)$ & 13 & $1(7.7 \%)$ & 22 & $3(13.6 \%)$ & -0.534 & 1.000 \\
\hline $\mathrm{F}^{\mathrm{a}}(-) \mathrm{M}^{\mathrm{b}}(+)$ & 21 & $2(9.5 \%)$ & 12 & $2(16.7 \%)$ & -0.605 & 1.000 \\
\hline $\mathrm{F}^{\mathrm{a}}(+) \mathrm{M}^{\mathrm{b}}(+)$ & 2 & $0(0.0)$ & 3 & $0(0.0)$ & - & - \\
\hline $\mathrm{F}^{\mathrm{a}}(-) \mathrm{M}^{\mathrm{b}}(-)$ & 47 & $12(25.5 \%)$ & 69 & $3(4.3 \%)$ & 3.338 & 0.001 \\
\hline $\mathrm{B}^{\mathrm{c}}$ or $\mathrm{S}^{\mathrm{d}}(+)$ & 4 & $0(0.0)$ & 3 & $0(0.0)$ & - & - \\
\hline Children (+) & 0 & $0(0.0)$ & 0 & $0(0.0)$ & - & - \\
\hline \multicolumn{7}{|c|}{ Have meal with $H$. $p$-positive person } \\
\hline Yes & 2 & $0(0.0)$ & 5 & $0(0.0)$ & - & - \\
\hline No & 8 & $4(50.0 \%)$ & 10 & $0(0.0)$ & 2.535 & 0.011 \\
\hline Not sure & 45 & $9(20.0 \%)$ & 37 & $5(13.5 \%)$ & 0.777 & 0.437 \\
\hline
\end{tabular}

${ }^{a}$ Father; ${ }^{b}$ mother; ${ }^{\text {brothers; }}{ }^{\mathrm{d}}$ sisters. $Z$ test was used to compare the difference between groups. In dishware sharing, nausea, gastric diseases, families with gastric diseases, and families who had meal with $H$. pylori-positive person category, the related information of $1,2,4,5$, and 93 subjects was missed, respectively. 
TABLE 5: Logistic regression analysis between dental practice frequency per week and oral $H$. pylori infection.

\begin{tabular}{lcccrrrr}
\hline Variable & \multirow{2}{*}{ Partial regression coefficients } & Standard error & Wals $\chi^{2}$ & * value & OR & \multicolumn{2}{c}{ OR 95\% CI } \\
& & & & Lower & Upper \\
\hline Intercept & -5.995 & 2.382 & 6.333 & 0.012 & 0.002 & \\
DPF & 1.776 & 0.861 & 4.257 & 0.039 & 5.909 & 1.093 \\
DPF $^{2}$ & -0.152 & 0.073 & 4.330 & 0.037 & 0.859 & 0.745 & 0.991 \\
\hline
\end{tabular}

DPF: dental practice frequency per week.

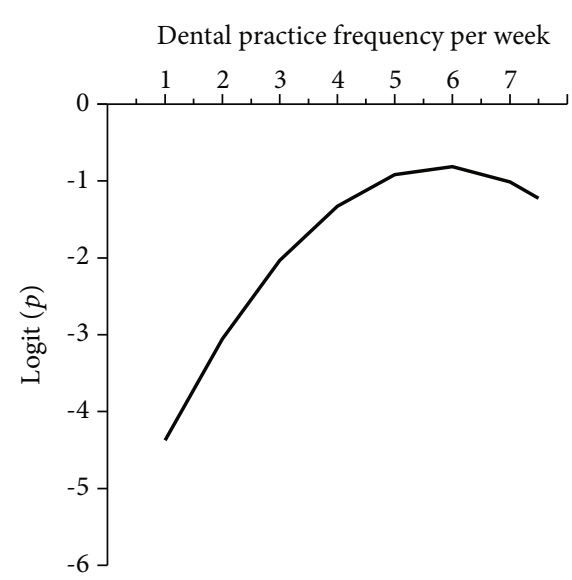

FIGURE 1: The fitting curve showing the association between the oral $H$. pylori infection possibility and dental practice frequency per week of dentists.

However, it does not mean that PPE plays no role in preventing oral $H$. pylori transmission, as we noticed that dentists did not wear PPE all the time once they enter the dental clinic. In most cases, they used PPE, especially mask, only when they carried out dental procedures, which may reduce the protective function of PPE. Our data highlights the importance of standard precautions in preventing dentists from oral $H$. pylori infection, including intensive disinfection of the clinic as well as wearing PPE all the time.

\section{Conclusion}

Taken together, the current study confirmed that dental professionals are at a higher risk of $H$. pylori infection compared with nondentists. The frequency of exposure to a dental clinic of the Chinese dentists is the major risk factor for $H$. pylori infection.

\section{Data Availability}

The data used to support the findings of this study are available from the corresponding author upon request.

\section{Conflicts of Interest}

The authors declare that they have no conflicts of interest regarding the publication of this paper.

\section{Acknowledgments}

Dr. He would like to thank her son, Zhiqian Li (four years old this year), for his encouragement and support all the time. This work was supported by the National Natural Science Foundation of China (grant number 81600874), the research grant from the Science and Technology Department of Sichuan Province (grant numbers 2020YJ0240 and 2019YJ0074), and Research \& Develop Program, West China Hospital of Stomatology, Sichuan University (Grant No.: LCYJ9-16).

\section{References}

[1] J. R. Warren and B. Marshall, "Unidentified curved bacilli on gastric epithelium in active chronic gastritis," Lancet, vol. 1, no. 8336, pp. 1273-1275, 1983.

[2] I. Adler, A. Muino, S. Aguas et al., "Helicobacter pylori and oral pathology: relationship with the gastric infection," World Journal of Gastroenterology, vol. 20, no. 29, pp. 9922-9935, 2014.

[3] G. M. Forbes, M. E. Glaser, D. E. Cullen et al., "Duodenal ulcer treated with Helicobacter pylori eradication: seven-year followup," Lancet, vol. 343, no. 8892, pp. 258-260, 1994.

[4] T. L. Cover and R. M. Peek Jr., "Diet, microbial virulence, and Helicobacter pylori-induced gastric cancer," Gut Microbes, vol. 4, no. 6, pp. 482-493, 2014.

[5] A. Al Sayed, P. S. Anand, K. P. Kamath, S. Patil, R. S. Preethanath, and S. Anil, "Oral cavity as an extragastric reservoir of Helicobacter pylori," ISRN Gastroenterol, vol. 2014, article 261369, 16 pages, 2014.

[6] S. Krajden, M. Fuksa, J. Anderson et al., "Examination of human stomach biopsies, saliva, and dental plaque for Campylobacter pylori," Journal of Clinical Microbiology, vol. 27, no. 6, pp. 1397-1398, 1989.

[7] P. Nagy, S. Johansson, and M. Molloy-Bland, "Systematic review of time trends in the prevalence of Helicobacter pylori infection in China and the USA," Gut Pathogens, vol. 8, no. 1 , p. $8,2016$.

[8] M. B. Assumpcao, L. C. Martins, H. P. Melo Barbosa et al., "Helicobacter pylori in dental plaque and stomach of patients from northern Brazil," World Journal of Gastroenterology, vol. 16, no. 24, pp. 3033-3039, 2010.

[9] K. Khandaker, K. Palmer, M. Eastwood, A. Scott, M. Desai, and R. Owen, "DNA fingerprints of Helicobacter pylori from mouth and antrum of patients with chronic ulcer dyspepsia," Lancet, vol. 342, no. 8873, p. 751, 1993.

[10] H. Momtaz, N. Souod, H. Dabiri, and M. Sarshar, "Study of Helicobacter pylori genotype status in saliva, dental plaques, stool and gastric biopsy samples," World Journal of Gastroenterology, vol. 18, no. 17, pp. 2105-2111, 2012. 
[11] K. Yang, Y. Li, and X. Zhou, "Overview of researches for Helicobacter pylori in oral cavity and stomach," West China Journal of Stomatology, vol. 32, no. 3, pp. 314-318, 2014.

[12] Y. Liu, H. Lin, Y. Bai et al., "Study on the relationship between Helicobacter pylori in the dental plaque and the occurrence of dental caries or oral hygiene index," Helicobacter, vol. 13, no. 4 , pp. 256-260, 2008.

[13] D. Gulseren, A. Karaduman, D. Kutsal, and R. M. Nohutcu, "The relationship between recurrent aphthous stomatitis, and periodontal disease and Helicobacter pylori infection," Clinical Oral Investigations, vol. 20, no. 8, pp. 2055-2060, 2016.

[14] R. Rajendran, R. Rajeev, S. Anil, M. Alasqah, and A. G. Rabi, "Helicobacter pylori coinfection is a confounder, modulating mucosal inflammation in oral submucous fibrosis," Indian Journal of Dental Research, vol. 20, no. 2, pp. 206211, 2009.

[15] H. Miyabayashi, K. Furihata, T. Shimizu, I. Ueno, and T. Akamatsu, "Influence of OralHelicobacter pylorion the success of eradication therapy against GastricHelicobacter pylori," Helicobacter, vol. 5, no. 1, pp. 30-37, 2001.

[16] Y. Niv, "H pylori recurrence after successful eradication," World Journal of Gastroenterology, vol. 14, no. 10, pp. 14771478, 2008.

[17] I. Adler, V. C. Denninghoff, M. I. Alvarez, A. Avagnina, R. Yoshida, and B. Elsner, "Helicobacter pylori associated with glossitis and halitosis," Helicobacter, vol. 10, no. 4, pp. 312317, 2005

[18] L. T. Rasmussen, R. W. d. Labio, L. L. Gatti et al., "Helicobacter pylori detection in gastric biopsies, saliva and dental plaque of Brazilian dyspeptic patients," Memórias do Instituto Oswaldo Cruz, vol. 105, no. 3, pp. 326-330, 2010.

[19] M. Umeda, H. Kobayashi, Y. Takeuchi et al., "High prevalence of Helicobacter pylori detected by PCR in the oral cavities of periodontitis patients," Journal of Periodontology, vol. 74, no. 1, pp. 129-134, 2003.

[20] R. Brgers, W. Schneider-Brachert, U. Reischl et al., "Helicobacter pyloriin human oral cavity and stomach," European Journal of Oral Sciences, vol. 116, no. 4, pp. 297-304, 2008.

[21] Q. H. Zou and R. Q. Li, "Helicobacter pylori in the oral cavity and gastric mucosa: a meta-analysis," Journal of Oral Pathology \& Medicine, vol. 40, no. 4, pp. 317-324, 2011.

[22] M. Siddiq, Haseeb-ur-Rehman, and A. Mahmood, "Evidence of Helicobacter pylori infection in dental plaque and gastric mucosa," Journal of the College of Physicians and SurgeonsPakistan, vol. 14, no. 4, pp. 205-207, 2004.

[23] B. Shames, S. Krajden, M. Fuksa, C. Babida, and J. L. Penner, "Evidence for the occurrence of the same strain of Campylobacter pylori in the stomach and dental plaque," Journal of Clinical Microbiology, vol. 27, no. 12, pp. 2849-2850, 1989.

[24] P. S. Anand, K. P. Kamath, and S. Anil, "Role of dental plaque, saliva and periodontal disease in Helicobacter pylori infection," World Journal of Gastroenterology, vol. 20, no. 19, pp. 56395653, 2014.

[25] D. N. Taylor and M. J. Blaser, "The epidemiology of Helicobacter pylori infection," Epidemiologic Reviews, vol. 13, no. 1, pp. 42-59, 1991.

[26] W. Schwizer, D. Menne, K. Schutze et al., "The effect of Helicobacter pylori infection and eradication in patients with gastrooesophageal reflux disease: a parallel-group, double-blind, placebo-controlled multicentre study," United European Gastroenterology Journal, vol. 1, no. 4, pp. 226-235, 2013.
[27] A. P. Thrift, N. Pandeya, K. J. Smith et al., "Helicobacter pylori infection and the risks of Barrett's oesophagus: a populationbased case-control study," International Journal of Cancer, vol. 130, no. 10, pp. 2407-2416, 2012.

[28] P. Malfertheiner, F. Megraud, C. A. O'Morain et al., "Management ofHelicobacter pyloriinfection-the Maastricht IV/ Florence consensus report," Gut, vol. 61, no. 5, pp. 646-664, 2012.

[29] W. D. Chey, B. C. Y. Wong, and Practice Parameters Committee of the American College of Gastroenterology, "American College of Gastroenterology guideline on the management of Helicobacter pylori infection," The American Journal of Gastroenterology, vol. 102, no. 8, pp. 1808-1825, 2007.

[30] G. Nardone, A. Rocco, D. Vaira et al., "Expression of COX-2, mPGE-synthase1, MDR-1 (P-gp), and Bcl-xL: a molecular pathway of $\mathrm{H}$ pylori-related gastric carcinogenesis," The Journal of Pathology, vol. 202, no. 3, pp. 305-312, 2004.

[31] T. Chiba, H. Marusawa, and T. Ushijima, "Inflammation-associated cancer development in digestive organs: mechanisms and roles for genetic and epigenetic modulation," Gastroenterology, vol. 143, no. 3, pp. 550-563, 2012.

[32] Y. Zhao, J. Zhang, A. S. L. Cheng, J. Yu, K. F. To, and W. Kang, "Gastric cancer: genome damaged by bugs," Oncogene, vol. 39, no. 17, pp. 3427-3442, 2020.

[33] G. Emilia, G. Longo, M. Luppi et al., "Helicobacter pylori eradication can induce platelet recovery in idiopathic thrombocytopenic purpura," Blood, vol. 97, no. 3, pp. 812-814, 2001.

[34] T. Takahashi, T. Yujiri, K. Shinohara et al., "Molecular mimicry by Helicobacter pylori CagA protein may be involved in the pathogenesis of $H$. pylori-associated chronic idiopathic thrombocytopenic purpura," British Journal of Haematology, vol. 124, no. 1, pp. 91-96, 2004.

[35] V. M. Cardenas, Z. D. Mulla, M. Ortiz, and D. Y. Graham, "Iron deficiency and Helicobacter pylori infection in the United States," American Journal of Epidemiology, vol. 163, no. 2, pp. 127-134, 2006.

[36] C. Hershko, A. V. Hoffbrand, D. Keret et al., "Role of autoimmune gastritis, Helicobacter pylori and celiac disease in refractory or unexplained iron deficiency anemia," Haematologica, vol. 90, no. 5, pp. 585-595, 2005.

[37] K. Kaptan, C. Beyan, A. U. Ural et al., "Helicobacter pylori-is it a novel causative agent in vitamin B12 deficiency?," Archives of Internal Medicine, vol. 160, no. 9, pp. 1349-1353, 2000.

[38] F. Franceschi, G. Zuccala, D. Roccarina, and A. Gasbarrini, "Clinical effects of Helicobacter pylori outside the stomach," Nature Reviews. Gastroenterology \& Hepatology, vol. 11, no. 4, pp. 234-242, 2014.

[39] K. S. Ahmed, A. A. Khan, I. Ahmed et al., "Prevalence study to elucidate the transmission pathways of Helicobacter pylori at oral and gastroduodenal sites of a south Indian population," Singapore Medical Journal, vol. 47, no. 4, pp. 291-296, 2006.

[40] S. L. Payao and L. T. Rasmussen, "Helicobacter pylori and its reservoirs: a correlation with the gastric infection," World J Gastrointest Pharmacol Ther, vol. 7, no. 1, pp. 126-132, 2016.

[41] R. Rautemaa, A. Nordberg, K. Wuolijoki-Saaristo, and J. H. Meurman, "Bacterial aerosols in dental practice - a potential hospital infection problem?," The Journal of Hospital Infection, vol. 64 , no. 1 , pp. 76-81, 2006.

[42] H. Yamada, K. Ishihama, K. Yasuda, Y. Hasumi-Nakayama, S. Shimoji, and K. Furusawa, "Aerial dispersal of bloodcontaminated aerosols during dental procedures," Quintessence International, vol. 42, no. 5, pp. 399-405, 2011. 
[43] R. Matsuda and T. Morizane, "Helicobacter pylori infection in dental professionals: a 6-year prospective study," Helicobacter, vol. 10, no. 4, pp. 307-311, 2005.

[44] K. Honda, T. Ohkusa, I. Takashimizu, M. Watanabe, and M. Amagasa, "High risk of Helicobacter pylori infection in young Japanese dentists," Journal of Gastroenterology and Hepatology, vol. 16, no. 8, pp. 862-865, 2001.

[45] S. K. Lin, J. R. Lambert, M. A. Schembri, L. Nicholson, and I. H. Johnson, "The prevalence of Helicobacter pylori in practising dental staff and dental students," Australian Dental Journal, vol. 43, no. 1, pp. 35-39, 1998.

[46] P. D. Marsh, "Role of the oral microflora in health," Microbial Ecology in Health and Disease, vol. 12, no. 3, pp. 130-137, 2009.

[47] N. Malathi, S. Mythili, and H. R. Vasanthi, "Salivary diagnostics: a brief review," ISRN Dentistry, vol. 2014, Article ID 158786, 8 pages, 2014.

[48] F. Chen, F. Welker, C. C. Shen et al., "A late Middle Pleistocene Denisovan mandible from the Tibetan Plateau," Nature, vol. 569, no. 7756, pp. 409-412, 2019.

[49] L. J. Castro-Munoz, C. A. Gonzalez-Diaz, A. Munoz-Escobar et al., "Prevalence of Helicobacter pylori from the oral cavity of Mexican asymptomatic children under 5 years of age through PCR," Archives of Oral Biology, vol. 73, pp. 55-59, 2017.

[50] N. Banatvala, Y. Abdi, L. Clements et al., "Helicobacter pylori infection in dentists-a case-control study," Scandinavian Journal of Infectious Diseases, vol. 27, no. 2, pp. 149-151, 2009.

[51] S. Kumar, D. C. Metz, S. Ellenberg, D. E. Kaplan, and D. S. Goldberg, "Risk Factors and Incidence of Gastric Cancer After Detection of_Helicobacter pylori_Infection: A Large Cohort Study," Gastroenterology, vol. 158, no. 3, pp. 527-536.e7, 2020.

[52] A. Sonnenberg, K. O. Turner, and R. M. Genta, "Low prevalence of Helicobacter pylori-positive peptic ulcers in private outpatient endoscopy centers in the United States," The American Journal of Gastroenterology, vol. 115, no. 2, pp. 244-250, 2020.

[53] C. de Martel, D. Georges, F. Bray, J. Ferlay, and G. M. Clifford, "Global burden of cancer attributable to infections in 2018: a worldwide incidence analysis," The Lancet. Global Health, vol. 8, no. 2, pp. e180-e190, 2020.

[54] C. Li, P. R. Musich, T. Ha et al., "High prevalence of Helicobacter pylori in saliva demonstrated by a novel PCR assay," Journal of Clinical Pathology, vol. 48, no. 7, pp. 662-666, 1995.

[55] Q. Song, B. Haller, R. M. Schmid, G. Adler, and G. Bode, "Helicobacter pylori in dental plaque: a comparison of different PCR primer sets," Digestive Diseases and Sciences, vol. 44, no. 3, pp. 479-484, 1999. 